\title{
Seismic noise changes during COVID-19 pandemic: a case study of Shillong, India
}

\author{
Surendra Nadh Somala ${ }^{1}$
}

Received: 9 April 2020 / Accepted: 2 May 2020 / Published online: 14 May 2020

(c) Springer Nature B.V. 2020

\begin{abstract}
The coronavirus pandemic has prompted several governments to take the major step of asking everyone to stay home except for essential needs. This has brought down the ground vibration significantly, in various frequency bands, particularly at higher frequencies related to anthropogenic seismic noise. The power is reduced by $5 \mathrm{~dB}$ at $10 \mathrm{~Hz}$ in Shillong, India, post-lockdown (after 25 March 2020) in India. This is lower than the levels that are observed over the weekends. On the day of Janata Curfew (22 March 2020), the reduction in power is $\sim 10 \mathrm{~dB}$ at $10 \mathrm{~Hz}$.
\end{abstract}

Keywords COVID $\cdot$ Corona $\cdot$ Shillong $\cdot$ Noise spectra $\cdot$ Seismic noise

\section{Introduction}

The COVID-19 disaster came to light in late 2019 when Wuhan of China saw a drastic increase in the number of people who tested positive for the novel coronavirus. Other parts of the world did not realize this until March 2020 when a few other countries reported significant number of cases. In a world where people interact with several others at work and leisure, the only way to flatten the exponential increase of cases due to human-human transmission of this virus is by maintaining social distancing. When the number of people suffering from this virus goes unmanageable for the lack of sufficient medical infrastructure, a country like India with population in excess of a billon had to announce complete lockdown starting 25 March 2020. Due to this lockdown, shopping malls, movie theatres, schools, etc., had to remain closed. Trains, buses and even aircrafts were halted to reduce large gathering. Except medical stores, and a few other basic needs, nothing could remain open. Factories and heavy machinery are no exemption for this closure. The implications for this lockdown were human-induced ground vibration having a dramatic reduction.

Anthropogenic seismic noise is prominent in high frequencies $(\sim 10 \mathrm{~Hz})$ and can be easily observed in the probably density functions of noise power of any seismic station, in various frequency bands. This is also the frequency regime of body waves of small magnitude

Surendra Nadh Somala

surendra@iith.ac.in

1 Department of Civil Engineering, Indian Institute of Technology Hyderabad, Hyderabad 502285, India 
$(M<2)$ earthquakes. The other extreme could be the long-period motion $(\sim 100 \mathrm{~s})$ from teleseismic waves. The frequencies in between are affected by a wide range of phenomenon. In this study, by considering the seismic data of a station in India that is readily accessible, we analyse the amount of reduction in ambient noise, in various frequency bands, particularly the anthropogenic regime, due to the lockdown period and the "Janata Curfew" of 22 March 2020.

\section{Noise spectra}

The daily power spectral density for the three components of seismic data recorded at Shillong $\left(25.567^{\circ} \mathrm{N} 91.856^{\circ} \mathrm{E}\right)$ is monitored continuously at a rate of 100 samples per second since its installation in the late 2007. The instrument is Nanometrics Trillium make, whose response is flat down to $240 \mathrm{~s}$. The ambient noise spectral power at six different widely separated frequencies $(0.01 \mathrm{~Hz}, 0.032 \mathrm{~Hz}, 0.1 \mathrm{~Hz}, 0.154 \mathrm{~Hz}, 1.037 \mathrm{~Hz}$ and $9.87 \mathrm{~Hz})$ is shown for all three components starting from 1 March 2020 till the first week of April 2020 as shown in Fig. 1. The spectral power at $9.87 \mathrm{~Hz}$ has taken a sharp dip on the 22 March 2020 in EW, NS and vertical direction. This was the day the Prime Minister of India announced what he termed as "Janata Curfew", self-imposed lockdown of people for a day. On this day, people were asked to remain indoors all day. Incidentally, it was also a Sunday. Figure 1 also includes three other Sundays, i.e. 1, 8 and 15 March 2020. However, the dip by $10-15 \mathrm{~dB}$ on the Janata Curfew Sunday is not the typical of other weekends. On 23 March, power levels appear to be catching up with those of background noise levels. However, the complete lockdown of India started on the 25 March 2020 and is still ongoing. Ever since the 25 March, the background seismic noise levels in Fig. 1 in all three directions have remained lower by about $5 \mathrm{~dB}$ as compared with the first couple of weeks of March.

Figure 2 shows probability density over the a broad range (0.1-100 s) periods for two weeks during early March (before lockdown) and couple of weeks beginning with the lockdown day (25 March). The only perceivable difference of post-lockdown weeks with respect to pre-lockdown is only that the maximum is on the higher side. Extrema can be related to some isolated events. For instance, maximum being on the higher side for postlockdown period can be related to the $M_{\mathrm{w}} 7.5$ Kuril Islands earthquake whose hypocentral distance to Shillong is about $6150 \mathrm{~km}$.

Finally, the spectrograms for the month of March and the first week of April are shown in Fig. 3. Once again the Janata Curfew day stands out with its lower power in higher frequencies $(\sim 10 \mathrm{~Hz})$. The power at $1 \mathrm{~Hz}$ also appears to be lower after the lockdown day and is evident more prominently in the vertical component. It is, however, Fig. 1 that allows for quantification of this reduction in power spectra.

\section{Conclusion}

Ambient vibration has reduced across the world due to the lockdown, which is different from country to country. Apart from helping in quantifying the noise power of a site and providing ground vibration records in the event of an earthquake, seismic data of broadband sensors can also help in identifying the human contribution to background seismic noise during rare disasters like COVID-19 that lead to lockdown. Anthropogenic noise in 
Daily PDF Mode Timelines

IN.SHL..HHE.M : 2020-03-01 to 2020-04-06

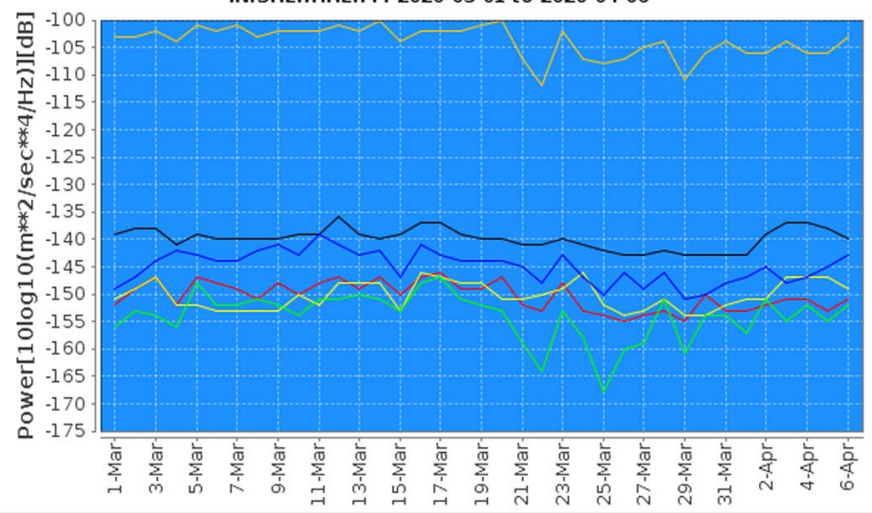

$103.75 \mathrm{Sec}(0.010 \mathrm{~Hz})=30.84 \mathrm{Sec}(0.032 \mathrm{~Hz}) \quad 10.00 \mathrm{Sec}(0.100 \mathrm{~Hz}) \mathbf{0} 6.48 \mathrm{Sec}(0.154 \mathrm{~Hz})$

$0.96 \mathrm{Sec}(1.037 \mathrm{~Hz})=0.10 \mathrm{Sec}(9.870 \mathrm{~Hz})$

Daily PDF Mode Timelines

IN.SHL...HHN.M : 2020-03-01 to 2020-04-06

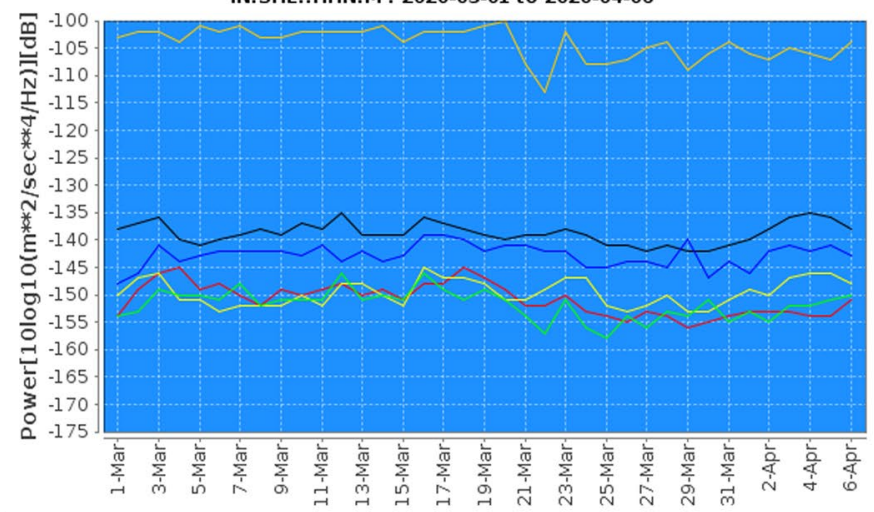

- $103.75 \mathrm{Sec}(0.010 \mathrm{~Hz})=30.84 \mathrm{Sec}(0.032 \mathrm{~Hz}) \quad 10.00 \mathrm{Sec}(0.100 \mathrm{~Hz}) \mathbf{\square} 6.48 \mathrm{Sec}(0.154 \mathrm{~Hz}$ $\square 0.96 \operatorname{Sec}(1.037 \mathrm{~Hz})=0.10 \mathrm{Sec}(9.870 \mathrm{~Hz})$

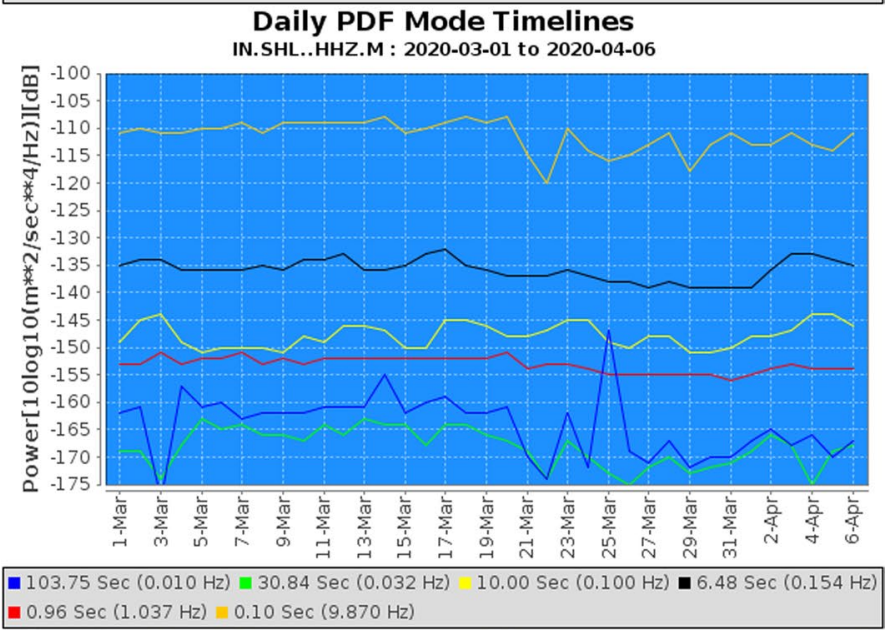

Fig. 1 Daily noise spectra of SHL seismic station, India, at six different frequencies for the three components from 1 March to 6 April 2020 (lockdown is from 25 March in India; Janata Curfew: 22 March) 

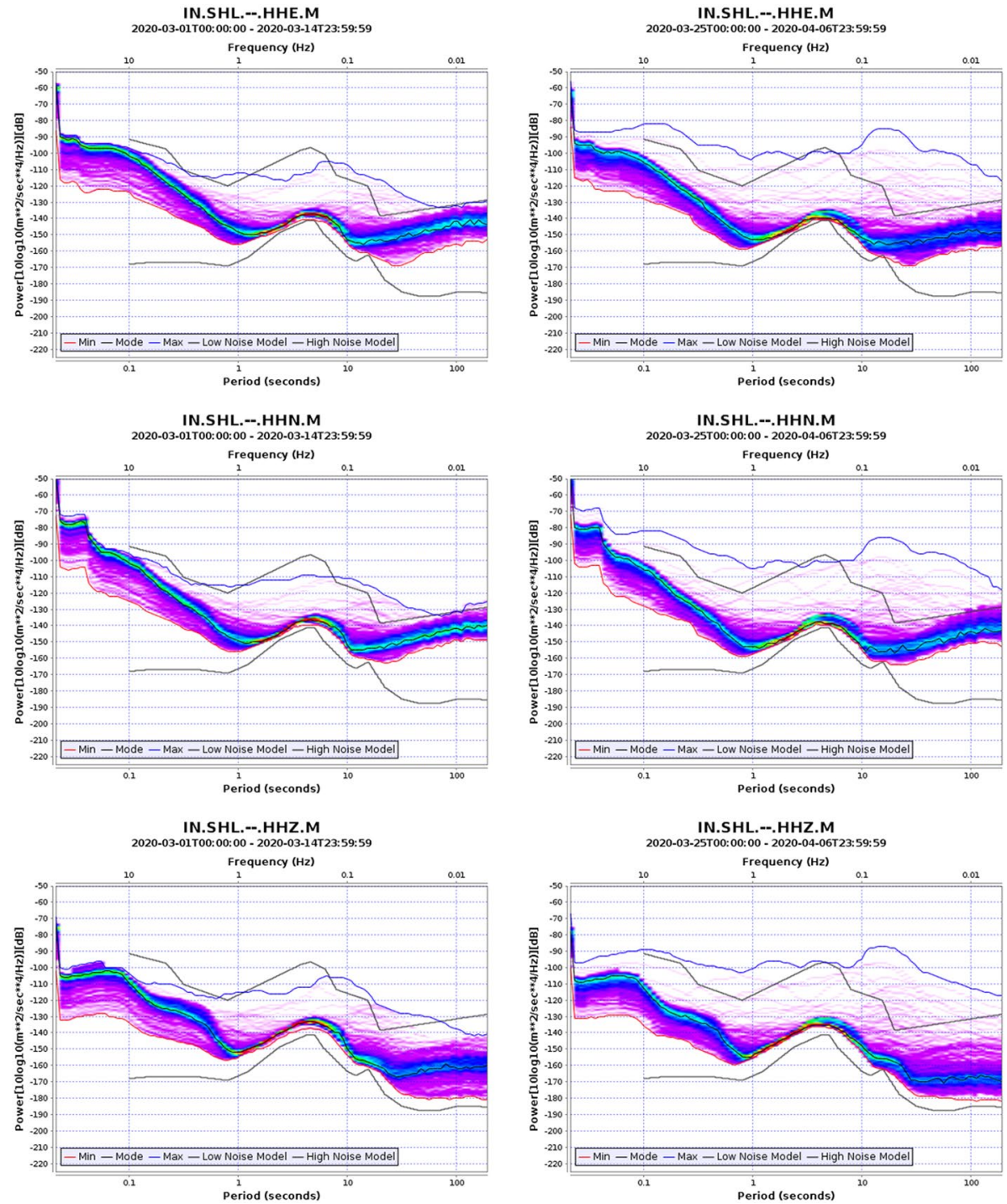

Fig. 2 Noise spectra for couple of weeks (left) before lockdown 1-14 March 2020 (right) after lockdown 25 March-6 April 2020 

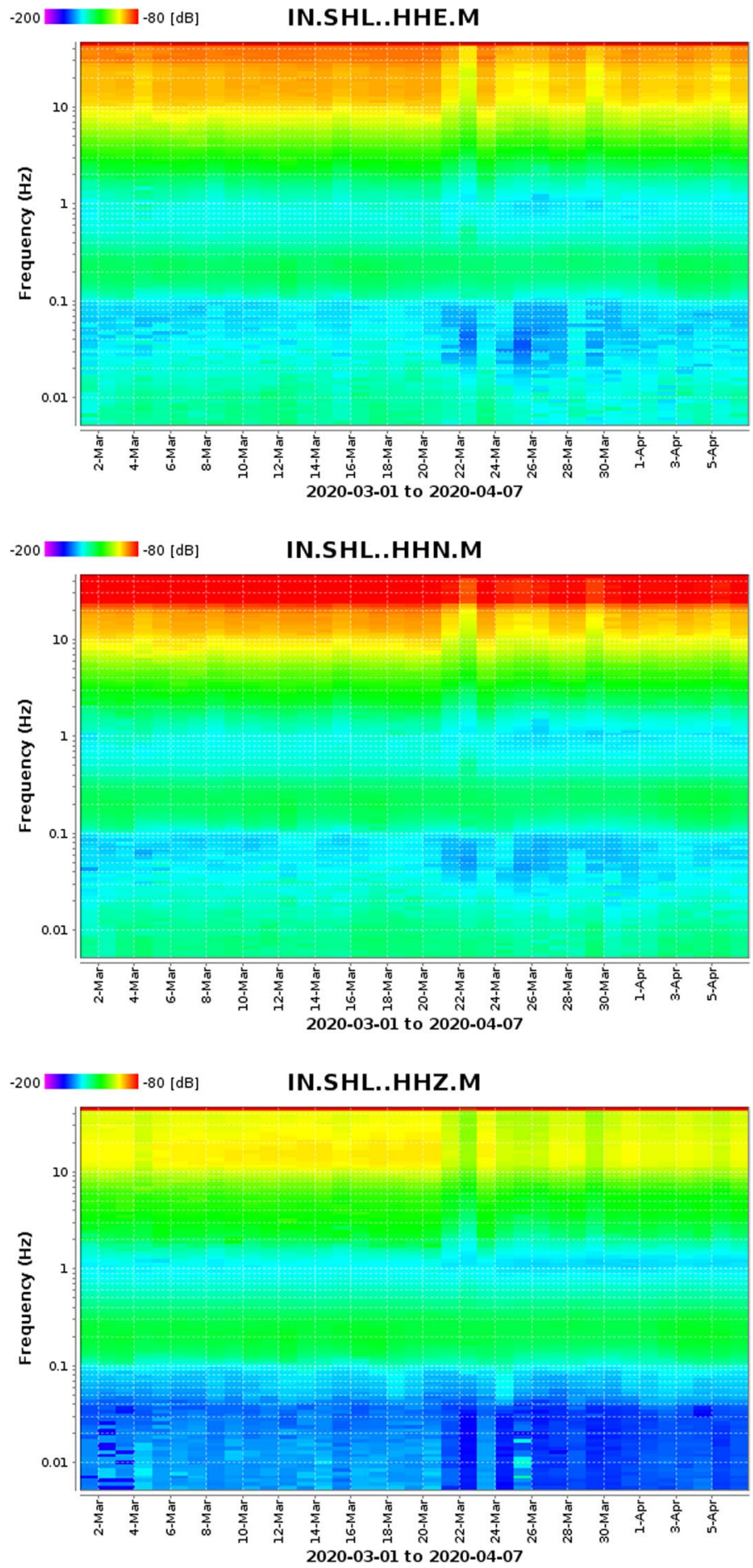

Fig. 3 Spectrograms for the three components at Shillong from 1 March-6 April 2020 (lockdown is from 25 March in India; Janata Curfew: 22 March) 
Shillong, India, is found to be anywhere from 5-10 dB at $10 \mathrm{~Hz}$. Similar analysis can be conducted for other countries of the world, if they had announced lockdown, in figuring out the human contribution to ground vibrations.

Acknowledgements This work is partially funded by the Department of Science and Technology, India, INT/RUS/RFBR/P-335 and Ministry of Earth Sciences MoES/P.O(Seismo)/1(304)/2016

Publisher's Note Springer Nature remains neutral with regard to jurisdictional claims in published maps and institutional affiliations. 